\title{
Investigation on Performance and Emission Characteristics of Low Heat Rejection Diesel Engine using Alternate Fuels
}

\author{
B.Anil Kumar"** and K.Vijaya Kumar Reddy^ \\ \#Department of Mechanical Engineering, Aurora's Technological and Research Institute, Parvathapur, Hyderabad-500 098, Telangana, India \\ $\wedge^{\wedge}$ Department of Mechanical Engineering, JNTUH College of Engineering, Hyderabad, India,
}

Received 02 May 2018, Accepted 28 June 2018, Available online 30 June 2018, Vol.8, No.2 (June 2018)

\begin{abstract}
Petroleum based fuels play a vital role in rapid depletion of conventional energy sources along with increasing demand and also major contributors of air pollutants. Major contributors of today's energy demand in India is being met with fossil fuels hence it is high time that alternative fuels for engines should be derived from indigenous sources .The enormous growth of world population, increased technical development and standard of living in industrial nations has led to this intricate situation in the field of energy, supply and demand. As India is agricultural country there is wide scope for the production of vegetable oils (both edible \& non edible oils) from different oil seeds. The present work is focused only on non-edible oils as fuels for engines, as the edible oils are in great demand and far too expensive. All neat oils are to be collected and converted into their respective methyl esters through transesterification process. Thermal barrier coatings are becoming increasingly important in providing thermal insulation for heat engine components. Thermal insulation reduces in-cylinder heat transfer from the engine combustion chamber as well as reducing component structural temperatures. Likewise, Bio-diesel too has a potential as a promising alternative fuel to their diesel counterparts while being renewable, sustainable, and environmental friendly. In this work, the comparative effect of performance and emission characteristics of a standard compression ignition engine (STD) with Magnesium stabilized Zirconia (MSZ) coated (LHR) engines are investigated. Fuel-related properties have to be calculated and analyzed with those of conventional diesel engine. The effect of use of bio-diesel fuel on engine power, fuel consumption and thermal efficiency has to be calculated and analysed with that of conventional diesel engine.
\end{abstract}

Keywords: Magnesium Stabilized Zirconia (MSZ), Bio-Diesel, Animal Tallow Methyl Ester, Low Heat Rejection Engines.

\section{Introduction}

Energy is a critical input for economic growth and sustainable development in both developed and developing countries. The world's energy requirement for transportation is met from non-renewable fossil fuels. The sharp rise in crude oil prices from US\$20 a barrel in 2002 to almost US\$100 (even touching US $\$ 140$ before stabilizing at around US\$80) has forced nations to seriously consider alternative energy sources that are renewable and non-polluting. In the face of shrinking supplies and rising demand, oil prices are expected to continue to rise. In addition, growing concerns about human-induced climate change, as evidenced by rising temperatures and environmental pollution, are further driving the impetus for nonpolluting energy sources. One such source is ethanol from plant biomass/grain and biodiesel from processing edible and non-edible vegetable oils.
The world is presently confronted with the twin crises of fossil fuel depletion and environmental degradation. The fuels of bio origin can provide a feasible solution of this worldwide petroleum crisis (Matthias L, 2008; Agarwal AK., 2006).

Recently, developing countries such as India and China have experienced a significant increase in energy demand. In addition, some of the world's largest producers of oil have suffered from warfare and political and social instability. Diminishing fossil fuel resources, coupled with the steady increase in energy consumption, has spurred research interest in alternative and renewable energy sources. Biodiesel is among the most promising fossil fuel alternatives. Potentially, there is a very large market for alternative fuels. According to International Energy Outlook 2006 report, the global demand for oil will grow from 80 million barrels per day in 2003 to 98 million barrels per day in 2015 and 118 million barrels per day in 2030. Although current oil prices are already 35\% higher than the 2025 projected prices of the previous 
year, global demand for oil continues to rise steadily. In order to meet the projected increase in world oil demand, total petroleum supply in 2030 will need to increase by 38 million barrels per day, from 80 million barrels in 2003 to 118 million barrels per day in 2030 . Members of the Organization of Petroleum Exporting Countries (OPEC) are expected to provide 14.6 million barrels per day of the increase. Higher oil prices have also induced substantial increase in non-OPEC oil production in the amount of 23.7 million barrels per day. A mandatory $5-10 \%$ blending of biofuels with petrol and diesel stipulated by some countries in the last 10-20 years triggered a rapid growth in the biofuel sector in the last decade. By 2007-08, world biofuel production had touched 62.2 billion tons $(\mathrm{t})$, of which around $88 \%$ was in the form of ethanol. The two largest ethanol producers, Brazil and the United States of America (USA), account for almost $87 \%$ of its total production. Biodiesel production that accounts for a smaller proportion of liquid biofuels, increased from 0.01 million tons in 1991 to 9.0 million tons by 2008 .

The European Union (EU) produces over $60 \%$ of the global share with a significantly smaller contribution coming from the USA (17\%). Key raw materials for bioethanol production are sugarcane in Brazil, corn in the USA, corn and wheat in China and molasses in India. However, the biofuel industry is still at a nascent stage requiring Government support in terms of lower taxes and other infant industry incentives. Since raw materials for biofuels originate from the farm sector, ensuring adequate incentives for farmers to grow biofuel crops without compromising on food security is critical. Several nations like the USA, Brazil, the Philippines and the European Union have in place biofuel policies that have a bearing right from the production of biofuel crops at the farm level to their conversion into transport grade biofuels at the distillery for use in blending.

\section{Literature Review}

\section{Thermal Barrier Coatings}

The quantity of the energy acquired from the fuel is not an intended level because of the factors in the combustion chamber of the engine. Some of the factors are, design of the combustion chamber, lack of adequate turbulence in the combustion chamber, poor oxygen at the medium, lower combustion temperature, compression ratio and advance of injection timing. It is thought that combustion temperature is the one of the most important factor among the aforementioned factors. All of the hydrocarbons cannot react with oxygen chemically during combustion time. With this aim, coating combustion chamber components with low thermal conductivity materials becomes a more important subject at these days. For this reason, combustion chamber components of the internal combustion engines are coated with ceramic materials using various methods (Hazar H, 2004).
A major breakthrough in diesel engine technology has been achieved by the pioneering work done by Kamo and Bryzik since 1978 to 1989 as the first persons in introducing TBC system for engines Kamo and Bryzik used thermally insulating materials such as silicon nitride for insulating different surfaces of the combustion chamber. Major promises of thermal barrier coated engines were increased thermal efficiency and elimination of the cooling system. A simple first law of thermodynamics analysis of the energy conversion process within a diesel engine would indicate that if heat rejection to the coolant was eliminated, the thermal efficiency of the engine could be increased (Boehman., 1997).Thermal barrier coatings were used to not only for reduced in-cylinder heat rejection and thermal fatigue protection of underlying metallic surfaces, but also for possible reduction of engine emissions (Chan S, 2000).Thermal insulation brings, according to the second law of thermodynamics, to engine heat efficiency improvement and fuel consumption reduction. Exhaust energy rise can be effectively used in turbocharged engines. Higher temperatures in the combustion chamber can also have a positive effect in diesel engines, due to the ignition delay drop and hardness of engine operation.

Vijay Kumar K. R. et al. conducted experiments on PZT Loaded Cyanate Modified Epoxy Coated Combustion Chamber and reported an improvement of $15.89 \%$ in brake specific fuel consumption, $5 \%$ for brake thermal efficiency and about $130^{\circ} \mathrm{C}$ rise in exhaust gas temperature at full load conditions.

Shrirao P.N. et al. investigated the potential of LHR engines on a tubocharged diesel engine and reported $2.18 \%$ decrease in specific fuel consumption and $12 \%$ increase in exhaust gas temperature at full load.

Morel et al. (1986) has analyzed that a significant part of the retained heat is directly converted to positive work. He has also examined that a typical highway truck engine with a practical zirconia coating able to achieve a $5 \%$ performance benefit over that of an engine cooled baseline at rated conditions

Debaish Das etal. conducted experiments on thermal barrier coated piston crown of diesel engine by varying the thickness of the coating and reported an increase in cylinder pressure and better heat release rate due to complete combustion.

Wong (1995) has considered different combinations of coatings with different thermal characteristics and coating thicknesses to predict the pattern of fuel consumption in IC engines. The simulation model developed by him considers the influence of transient heat transfer into and out of the combustion chamber surface throughout the entire engine operating cycle. The simulation also included an advanced liner friction model which accounts for the effects of liner surface temperatures and lubricating oil viscosity.

So far, numbers of experimental and analytical studies related to the use of ceramic materials in 
engines have focused on diesel engines but relatively very few on spark-ignition engines.

Results of the analysis showed that all thermal barrier coating materials provided a performance benefit that is strongly dependent on the coating thickness. Most coatings for the piston and head face surfaces provided a maximum benefit at a coating thickness of $0.1 \mathrm{~mm}$. The predicted maximum benefit in thermal performance is found to range from $1 \%$ to $2 \%$. It is predicted that a coating thickness of $0.5 \mathrm{~mm}$ in the liner would provide an optimum oil viscosity and a reduced friction with a $5 \%$ increase in performance.

\section{Importance of TBC in Diesel Engines}

Energy conservation and efficiency have always been the quest of engineers concerned with internal combustion engines. Even the petrol engine rejects about two thirds of the heat energy of the fuel, onethird to the coolant, and one third to the exhaust, leaving only about one-third as useful power output. Theoretically if the heat rejected could be reduced, then the thermal efficiency would be improved. Low Heat Rejection engines aim to do this, by reducing the heat lost to the coolant.

A typical TBC system consists of (i) the top coat (TC), a porous ceramic layer that acts as the insulator, (ii) the bond coat (BC), an oxidation-resistant metallic layer between the substrate and the TC and (iii) the super alloy or other material substrate that carries the structural load (P.N. Shrirao, 2011).

At times, single Top Coat layer composition does not satisfy multifunctional requirements. As a result, double ceramic coating system has evolved. In this two or three top coats may be applied to suit the operation conditions. Researchers found by the doping of certain elements, the thermal expansion coefficient of $\mathrm{La}_{2} \mathrm{Zr}_{2} \mathrm{O}_{7}$ can be increased. When its thermal expansion coefficient is increased to a value similar to that of YSZ, the $\mathrm{La}_{2} \mathrm{Zr}_{2} \mathrm{O}_{7}$ coating can be hopefully used in high temperature applications. On the other hand, as the dual layer MCrAlY/YSZ system seems to reach their optimum performance, the development of TBCs must shift towards different materials combinations and deposition processes. It seems that the concept of multilayer is effective for the improvement of the thermal shock life of TBCs because no single material satisfies all requirements for TBCs. The multilayer includes an erosion resistant layer as the outer layer, a thermal barrier layer, a corrosion-oxidation resistant layer, a thermal stress control layer and a diffusion resistant layer.

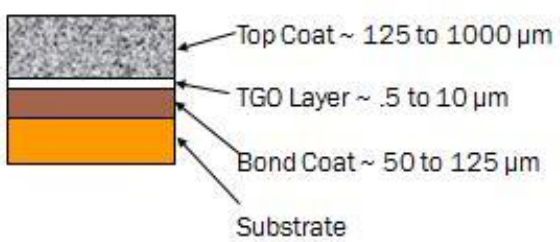

Fig 2.1: Layers of TBC
Excellent and the $\mathrm{CeO}_{2} / 8 \mathrm{YSZ}$ coating showed a good thermal shock resistance. Taken in total, several decades of TBC development indicate that when all of the necessary properties for successful TBCs considered, YSZ remains difficult to be replaced

Some advantages of thermal barrier coatings on diesel engines are below.

- Low cetane fuels can be burnt,

- Improvements occurs at emissions except NOx,

- Waste exhaust gases are used to produce useful shaft work,

- Increased effective efficiency,

- Increased thermal efficiency.

- Using lower-quality fuels within a wider distillation range,

- The ignition delay of the fuel is considerably reduced,

- The faster vaporization and the better mixing of the fuel,

- Reduced specific fuel consumption,

- Multi-Fuel capability,

- Improved reliability,

- Smaller size,

- Lighter weight,

- Decreased the heat removed by the cooling system

\section{Bio-diesel}

Biodiesel is an oxygenated fuel; emissions of carbon monoxide and soot tend to reduce. The use of biodiesel can extend the life of diesel engines because it is more lubricating than petroleum diesel fuel. Biodiesel is produced from renewable vegetable oils/animal fats and hence improves the fuel or energy security and economy independence. A lot of research work has been carried out to use vegetable oil both in its neat form and modified form. Since India is net importer of vegetable oils, edible oils cannot be used for production of biodiesel. India has the potential to be a leading world producer of biodiesel, as biodiesel can be harvested and Sourced from non-edible oils.

\section{Transesterification Process}

Transesterification of natural glycerides with methanol to methyl esters is a technically important reaction that has been used extensively in the soap and detergent manufacturing industry worldwide for many years. Almost all biodiesel is produced in a similar chemical process using base catalyzed trans esterification as it is the most economical process, requiring only low temperatures and pressures while producing a $98 \%$ conversion yield.

The transesterification process is the reaction of a triglyceride (fat/oil) with an alcohol to form esters and glycerol. A triglyceride has a glycerin molecule as its base with three long chain fatty acids attached. The characteristics of the fat are determined by the nature 
of the fatty acids attached to the glycerin. The nature of the fatty acids can, in turn, affect the characteristics of the biodiesel. During the esterification process, the triglyceride is reacted with alcohol in the presence of a catalyst, usually a strong alkaline like sodium hydroxide. The alcohol reacts with the fatty acids to form the mono-alkyl ester, or biodiesel, and crude glycerol. In most production, methanol or ethanol is the alcohol used (methanol produces methyl esters, ethanol produces ethyl esters) and is base catalyzed by either potassium or sodium hydroxide. Potassium hydroxide has been found more suitable for the ethyl ester biodiesel production, but either base can be used for methyl ester production. The figure below shows the chemical process for methyl ester biodiesel. The reaction between the fat or oil and the alcohol is a reversible reaction, so the alcohol must be added in excess to drive the reaction towards the right towards the right and ensure complete conversion. The products of the reaction are the biodiesel itself and glycerol. A successful Trans-esterification reaction is signified by the separation of the methyl ester (biodiesel) and glycerol layers after the reaction time.
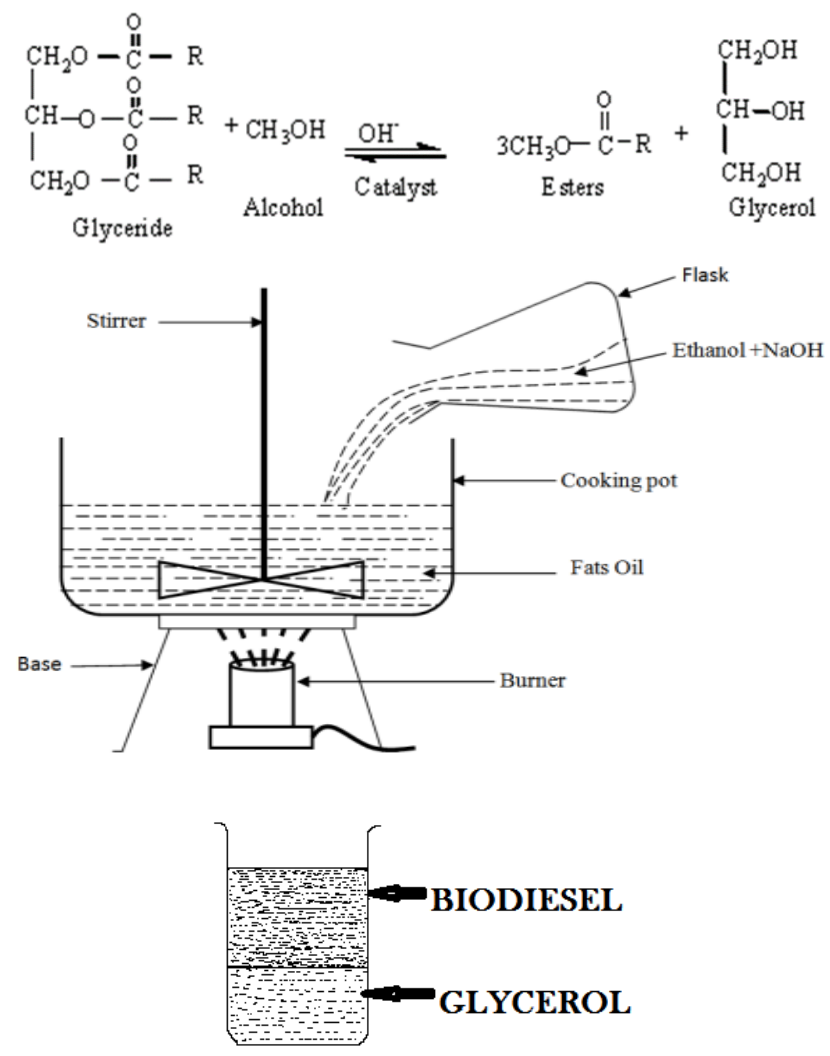

Figure 2.2: Production of Biodiesel

The heavier co-product, glycerol, settles out and may be sold as is or purified for use in other industries, e. Biodiesel has a viscosity similar to petroleum diesel and can be used as an additive in formulations of diesel to increase the lubricity. Biodiesel can be used in pure form (B100) or may be blended with petroleum diesel at any concentration in most modern diesel engines. Biodiesel will degrade natural rubber gaskets and hoses in vehicles (mostly found in vehicles manufactured before 1992), although these tend to wear out naturally and most likely will have already been replaced with Viton type seals and hoses which are nonreactive to biodiesel. Biodiesel's higher lubricity index compared to petroleum diesel is an advantage and can contribute to longer fuel injector life.

Biodiesel is a better solvent than petroleum diesel and has been known to break down deposits of residue in the fuel lines of vehicles that have previously been run on petroleum diesel.

Fuel filters may become clogged with particulates if a quick transition to pure biodiesel is made, as biodiesel cleans the engine in the process. It is, therefore, recommended to change the fuel filter within 600-800 miles after first switching to a biodiesel blend.

Biodiesel's commercial fuel quality is measured by the ASTM standard designated D 6751. The standards ensure that biodiesel is pure and the following important factors in the fuel production process are satisfied:

- Complete reaction

- Removal of glycerin

- Removal of catalyst

- Removal of alcohol

- Absence of free fatty acids

- Low sulfur content

Biodiesel is, at present, the most attractive market alternative among the non-food applications of vegetable oils for transportation fuels. The different stages in the production of plant/seed oil methyl ester generate by-products which offer further outlets. Oil cake, the protein rich fraction obtained after the oil has been extracted from the seed, is used for animal feed. Glycerol, the other important by-product, has numerous applications in the oil and chemical industries such as the cosmetic, pharmaceutical, food, and painting industries.

\section{ATME fuels}

Animal Tallow Methyl Ester (ATME)

Animal Tallow used for production of Biodiesel Animal Tallow can be used for biodiesel production as easily as Plant Oils. About 14 MT of Tallow is available globally. Tallow as a unique feedstock has certain properties that are hard to reproduce from plant oils.

\section{Experimental setup}

The details of the experimental set up are presented in this chapter. The information about the engine, components, instrumentation and controls used in test engine are described. 


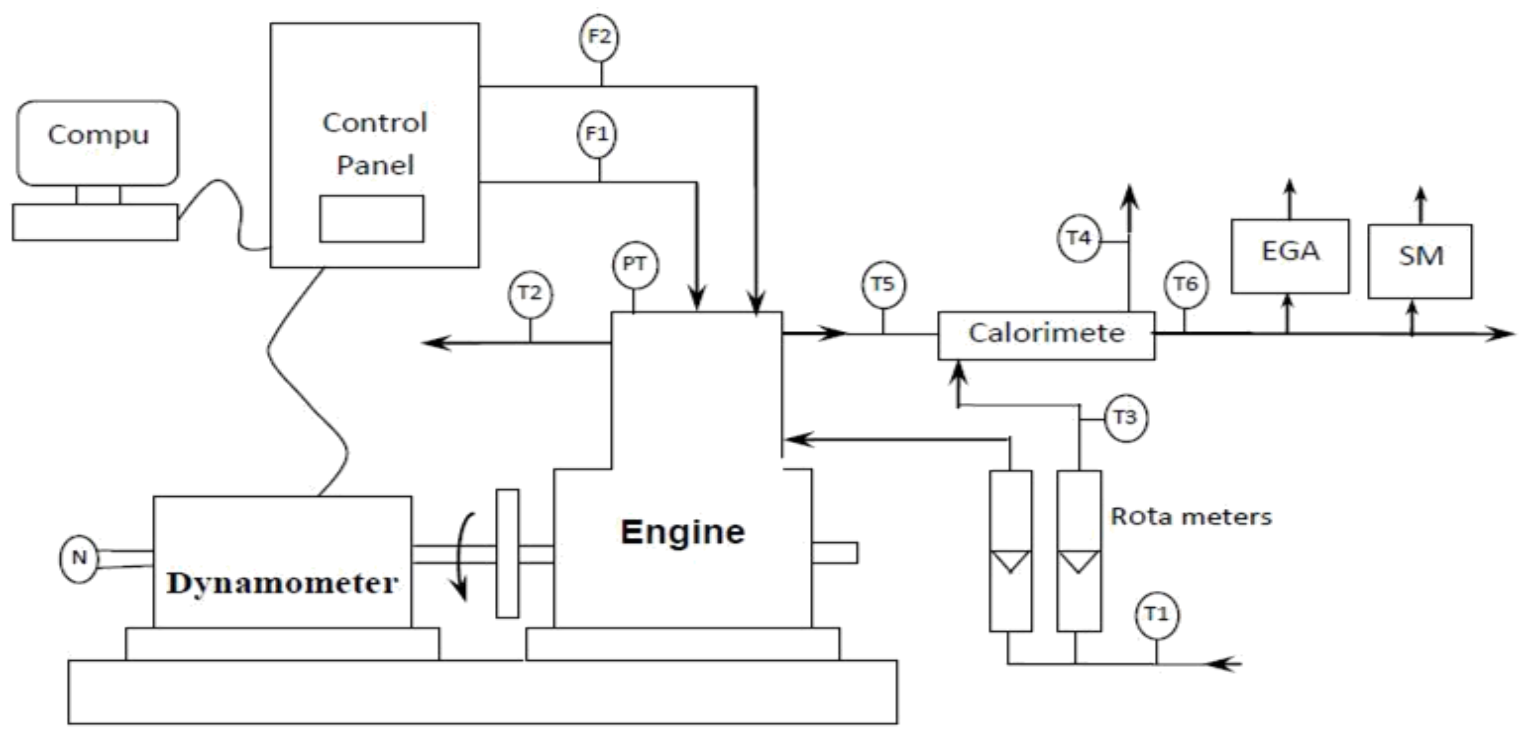

Figure 3.1: Line diagram of Experimental set up

\section{Experimental Set up}

The Kirloskar engine is one of the widely used engines in agriculture pump sets, farm machinery and medium scale commercial purposes. The setup consists of a single cylinder, four strokes, naturally aspirated, water cooled Diesel engine connected to eddy current dynamometer. This eddy current dynamometer is used for loading the engine. The engine is interfaced with Engine Soft Software for the measurement of combustion parameters. It is provided with necessary instruments for combustion chamber pressure and crank-angle measurements. For the measurement of cylinder pressure, a pressure transducer is fitted on the engine cylinder head and a crank angle encoder is used for the measurement of crank angle and TDC position. The pressure and crank angle signals are fed to a data acquisition card fitted with Pentium 4 personal computer. The engine speed is sensed and indicated by an inductive pick up sensor in conjunction with a digital rpm indicator, which is a part of eddy current dynamometer. The liquid fuel flow rate is measured on the volumetric basis using electronic transmitter. Provision is also made for interfacing airflow, temperatures and load measurement. The airflow is measured using an orifice meter and the exhaust gas temperatures are recorded with chromelalumel thermocouples. The setup has stand-alone panel box consisting of air box, fuel tank, manometer, fuel measuring unit, transmitters for air and fuel flow measurements, process indicator and engine indicator. Rotameters are provided for cooling water and calorimeter water flow measurement. A computerized Diesel injection pressure measurement can be conducted through sensor transmitters. The various components of experimental set up are described below. Fig.3.1 shows line diagram \& Fig.3.2 shows the photograph of the experimental set up.
The Instruments of the Experimental Setup are
1) The engine
2) Dynamometer
3) Exhaust gas analyser

The Engine

The Engine chosen to carry out experimentation is a single cylinder, four stroke, vertical, water cooled, direct injection computerized Kirloskar make CI Engine. This engine can withstand higher pressures encountered and also is used extensively in agriculture and industrial sectors. Therefore this Engine is selected for carrying experiments. Fig.3.3 shows the actual photos of the C.I. Engine and its attachment.

\section{Dynamometer}

The engine has a DC electrical dynamometer to measure its output. The dynamometer is calibrated statistically before use. The dynamometer is reversible i.e., it works as monitoring as well as an absorbing device. Load is controlled by changing the field current. Eddy-Current Dynamometer's theory is based on EddyCurrent (Fleming's right hand law). The construction of eddy-current dynamometer has a notched disc (rotor) which is driven by a prime mover (such as engine, etc.) and magnetic poles (stators) are located outside with a gap. The coil which excites the magnetic pole is wound in circumferential direction. When current runs through exciting coil, a magnetic flux loop is formed around the exciting coil through stators and a rotor. The rotation of rotor produces density difference, then eddy-current goes to stator. The electromagnetic force is applied opposite to the rotational direction by the product of this eddy-current. 


\section{Exhaust Gas Analyzer}

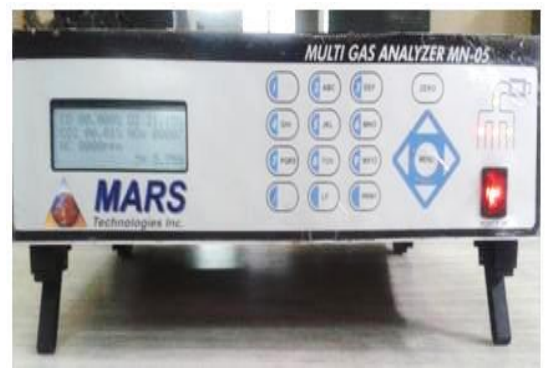

Figure 3.2: Five Gas Emission Analyzer

All emissions like Carbon monoxide, Carbon dioxide, Un-Burnt Hydrocarbons, Nitrogen oxide and unused oxygen are found in 5 gas emission analyzer of model MULTI GAS ANALYZER MN-05 is used. In this cable one end is connected to the inlet of the analyzer and the other end is connected at the end of the exhaust gas outlet. Continuous charging of the analyzer is essential to work in an effective way.Fig.3.4 show the actual photo of Exhaust Gas Analyzer. The measuring method is based on the principle of light absorption in the infrared region, known as non-dispersive infrared absorption. The broadband infrared radiation produced by the light source passes through a chamber filled with gas, generally methane or carbon dioxide. This gas absorbs radiation of a known wavelength and this absorption is a measure of the concentration of the gas. There is a narrow bandwidth optical filter at the end of the chamber to remove all other wavelengths before it is measured with a pyro-electric detector.

\section{Experimental Procedure}

In this work, the engine is maintained at $1500 \mathrm{rpm}$ throughout the experimentation and fixed injection pressure of 180 bar. The standard engine (STD) without coating is experimented at nine different loads in increasing order. For this, eddy current dynamometer is used. Emissions are recorded by Multi Gas Analyser MN -05. To attain the steady state, engine is put to idling for $15 \mathrm{~min}$ before every set of experimentation at minimum possible load.

Then the STD engine"s piston is uninstalled and replaced by MSZ coated piston turn by turn.

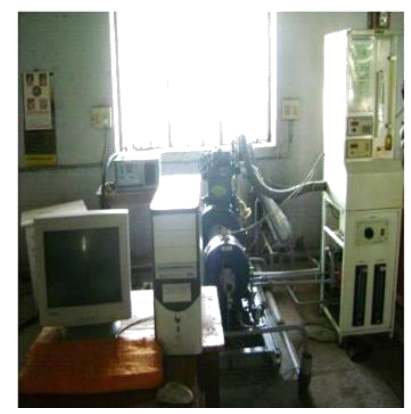

Figure 3.3: Experimental setup of computerized CI Engine
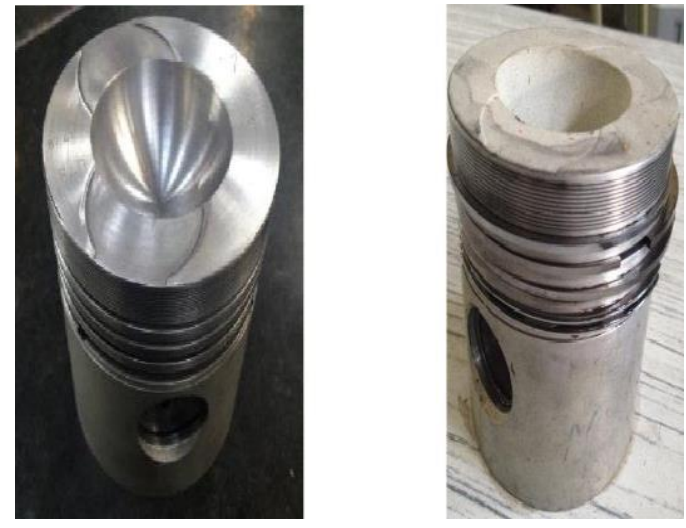

Figure 3.4: Uncoated and Coated piston Crowns

Then the same procedure is carried out. The modified engine (LHR) is compared for performance and emission characteristics with base line engine (STD) using Diesel, PSME and ATME fuels. Performance characteristics are recorded by GUI softwareEnginesoft by Apex technologies Ltd. In each set of test readings, fuel consumption, cylinder pressures at different crank angles, exhaust gas temperatures and concentrations of $\mathrm{CO}, \mathrm{CO}_{2}, \mathrm{HC}, \mathrm{NO}_{\mathrm{x}}$ emissions are taken at nine different loads.

\section{Investigation into performance and emissions characteristics}

Brake Thermal Efficiency (BTHE), Brake Specific Fuel Consumption (BSFC) and Exhaust Gas Temperature (EGT) are compared with Brake Power (BP) at nine different loads. These are visualized with the help of graphs.

Legend:

STD-DIESEL: Experimentation of Standard Engine (uncoated engine) fuelled with diesel

STD-ATME: Experimentation of Standard Engine fuelled with ATME

MSZ-DIESEL: Experimentation of MSZ coated Engine fuelled with diesel

MSZ-ATME: Experimentation of MSZ coated Engine fueled with ATME

\subsection{Brake Thermal Efficiency}

Fig 4.1 shows the variation of Brake Thermal Efficiency with Brake Power. There is an improvement in BTE for coated engine fueled with ATME when compared to normal engine. This is due to the improved combustion which is caused by greater oxygen content of biodiesel molecule and better ignition quality of ATME biodiesel BTE increases when the load is increased for a given fuel, because of, more power output due to efficient combustion caused by proper atomization and good combustible mixture formation at increased loads. 


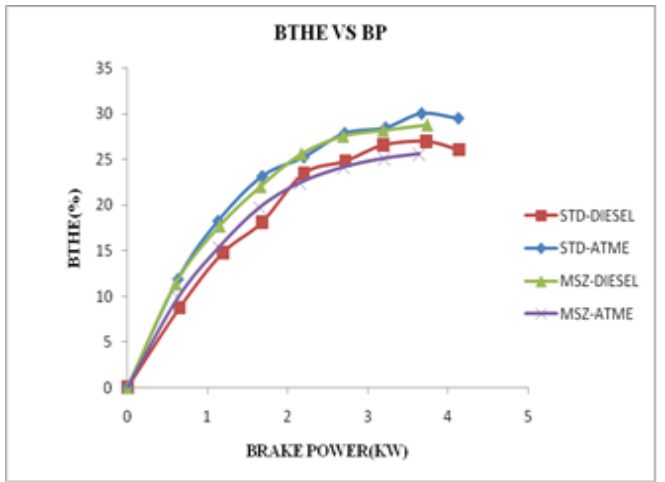

Figure 4.1: Variation of Brake Thermal Efficiency with Brake Power

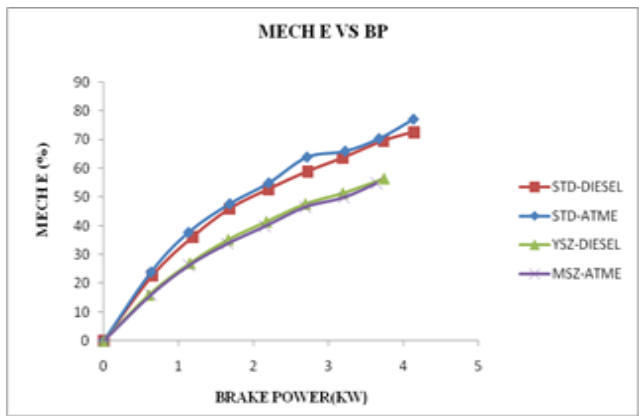

Figure 4.2: Variation of Mechanical Efficiency with Brake Power

\subsection{Mechanical efficiency}

Fig 4.2 shows the variation of Mechanical efficiency with Brake Power. The mechanical efficiency of diesel is slightly higher than the biodiesel in case of normal engine. Here we can see the effect of thermal barrier coating which increases the mechanical efficiency. This is due to fuel burning completely in LHR engine due increased temperature in combustion chamber.

\subsection{Carbon Dioxide}

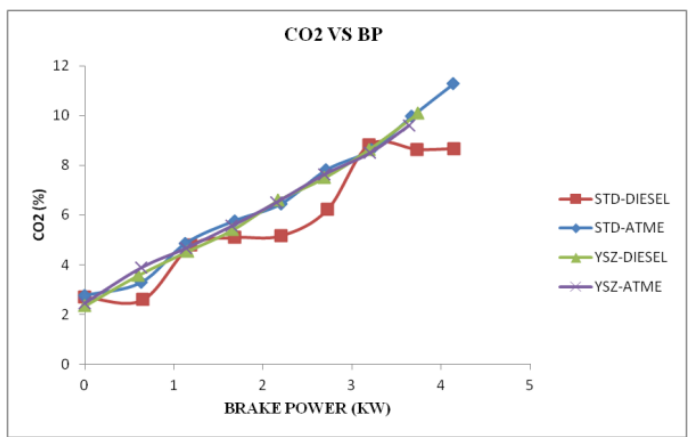

Figure 4.3: Variation of Carbon Dioxide with Brake Power

Fig 4.3 shows the variation of $\mathrm{CO}_{2}$ with $\mathrm{BP} . \mathrm{CO}_{2}$ emitted is proportional to fuel consumption. MSZ-ATME has lower $\mathrm{CO}_{2}$ concentration compared to normal engine as is evident. From fig 4.2.1. This may also be attributed to lower carbon content in bio-diesels. Approximately about $4 \%$ decrease in $\mathrm{CO}_{2}$ is observed for LHR-ATME when compared to baseline engine

\subsection{Carbon Monoxide}

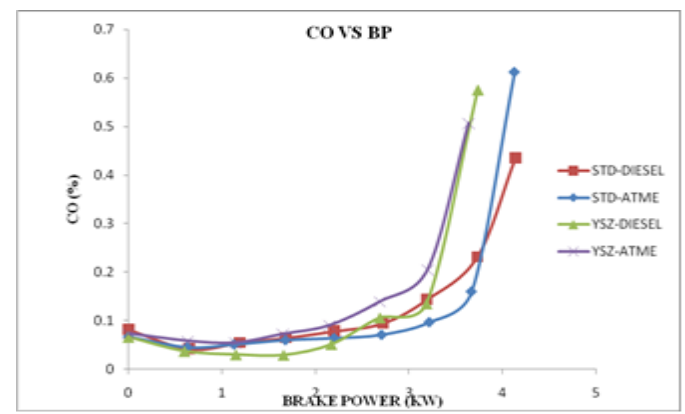

Figure 4.4: Variation of Carbon Monoxide with Brake Power

Fig 4.4 interprets the variation of $\mathrm{CO}$ with $\mathrm{BP}$ and substantiates the potential of LHR engines. Emissions of carbon monoxide from a D1 diesel engine mainly depend upon the fuel physical and chemical properties. It is well known that better combustion leads to lower concentrations of $\mathrm{CO}$ at the exhaust. The trend increases with increase in load as air-fuel ratio decreases by increase in load. LHR-ATME has least CO concentration and is startlingly much lower than the baseline engine. This is due to complete combustion in insulated environment of LHR engine and high oxygen content in bio-diesels. Further, ATME has high cetane number which reduces the possibility of formation of rich fuel zone which diminishes $\mathrm{CO}$ formation. This may also be attributed to lower carbon to hydrogen ratio in bio-diesel.

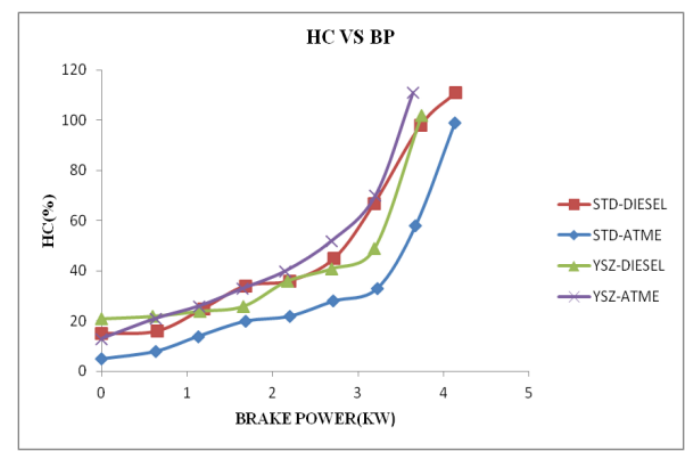

Figure 4.5: Variation of Un-burned Hydrocarbons with Brake Power

\subsection{Hydrocarbons}

Fig 4.5 shows the variation of $\mathrm{HC}$ with BP. Normally SI engines are emitting more $\mathrm{HC}$ and $\mathrm{CO}$ emissions whereas the CI engines are not so. HC emission is reduced in LHR -ATME engine due to high after combustion temperatures and stresses. In this 
phenomenon formation of rich air-fuel mixture plays a vital role. In bio-diesels this may be due to high cetane

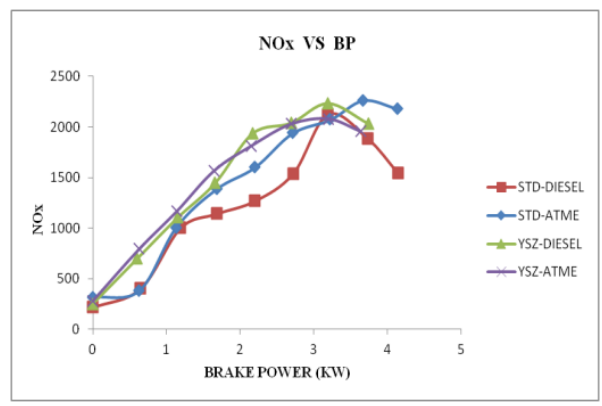

Figure4.6: Variation of Oxides of Nitrogen with Brake Power

number which decreases the quenching distance in high in-cylinder temperature environment of LHR engine

\subsection{Oxides of Nitrogen}

Fig 4.6 shows the variation of $\mathrm{NO}_{\mathrm{x}}$ with $\mathrm{BP}$. $\mathrm{NO}_{\mathrm{x}}$ is temperature sensitive. The high combustion temperatures, inherent availability of nitrogen and oxygen from fuel and intake charge create favorable conditions in accelerating the reaction to result into oxides of nitrogen. This is the reason for increased $\mathrm{NO}_{\mathrm{x}}$ concentrations in LHR engine. In bio-diesels, higher oxygen content increases injection advance thereby increasing chances for $\mathrm{NO}_{\mathrm{x}}$ formation. The trend for $\mathrm{NO}_{\mathrm{x}}$ at high loads is decreasing

\section{Conclusions}

In this work, conventional diesel engine is converted to thin ceramic coated LHR engine. The combined effect of coated engine powered with bio-diesel (ATME) is studied for performance and emission characteristics. The following conclusion can be drawn:

1) The production of biodiesel from animal fats is a new option and can be efficiently use in diesel engine. Advanced high performance ceramic coatings have opened for new opportunities.

2) Ceramic coatings provide potential for higher engine thermal efficiencies, longer life and higher reliability of engine components.

3) This work tacitly suggests that excess oxygen contents of biodiesel play a key role in Engine performance and biodiesel is proved to be a potential fuel for complete or partially replacement of diesel fuel. The oxygen content in the biodiesel results in better combustion and increases the Combustion chamber temperature, which leads to higher NOx emissions, especially at high engine loads. Exhibits eco-friendly system.

\section{References}

Matthias L, Thomas K, Thorsten S, Stefan P, Yunji C (2008); Tomorrows Diesel Fuel Diversity - Challenges and Solutions, SAE,1:1731

Agarwal AK (2006); Bio-fuels (alcohols and biodiesel) applications as fuels for internal combustion engines. International Journal Energy Combustion Science, 33:233-271

Acharya SS and Jogi RL (2004), Farm input subsidies in Indian agriculture. Agricultural Economics Research Review 17(1):11-41.

FAO (Food and Agriculture Organization)(2008) The state of food and agriculture. Rome, Italy: Food and Agriculture Organization. 128 pp.

GOI (Government of India) (2009) National Policy on Biofuels. New Delhi, India: Ministry of New and Renewable Energy. 18 pp.

Hazar H. ve Öner C (2004) Dizel motorlarında termal bariyer kaplamanın egzoz emisyonlarına etkisi Doğu Anadolu Bölgesi Araștırmaları, 48-51.

Boehman, A. L., Vittal, M., Borek, J. A., Marks, D. A. and Bentz, A. P. (1997), The effects of thermal barrier coatings on diesel engine emissions, ASME ICE-Vol 29-3, 25-32.

Chan S., H. and Khor K., A. (2000) The effect of thermal barrier coated piston crown on engine characteristics, Journal of Materials Engineering and Performance, 9(1), 103-109.

Miller, R.A. (1997), Thermal barrier coatings for aircraft engines: history and directions, Journal for Thermal Spray Technology, Vol.6 (1), pp. 35-42.

Miyari Y, Matsuhisa T and Ozawa T (1989), Selective Heat Insulation of Combustion Chamber Valves for DI Diesel Engine with Ceramics, Transaction of SAE.

Wong V (1995), Assessment of Thin Thermal Barrier Coatings for IC Engines, SAE Technical Paper-950980.

Vijaya Kumar K. R., Sundareswaran V. (2011), The Effect of Thermal Barrier Coatings on Diesel Engine Performance of PZT Loaded Cyanate Modified Epoxy Coated Combustion Chamber, Jordan Journal of Mechanical and Industrial Engineering, Vol. 5, pp. 403-406

P.N. Shrirao, A.N. Pawar (2011), Evaluation of performance and emission characteristics of Turbocharged diesel engine with Mullite as thermal barrier coating, International Journal of Engineering and Technology, Vol. 3, pp. 256-262.

Debaish Das, Gautam Majumdar, Rajat Shubra Sen, B.B. Ghosh (2013), Evaluation of combustion and emission characteristics on diesel engine with varying thickness of PSZ coated piston crown, International Journal of Innovative Research in Science, Engineering and Technology, Vol. 2, Issue 10, pp. 4858-4865

Saint-Ramond, B. High insulation termal barrier coating systems, Air \& Space Europe, 3, 3/4, (2001).

Bose S. (2007), High Temperature Coatings, 312 pages, Science Direct e-book Copyright

H.Samadi, and T.W. Coyle (2004), Alternative thermal barrier coatings for diesel engines, 5th Congress of Iran Ceramic Society, Iranian Ceramic Society, 1-8, Tehran, Iran

X.Q. Cao, R. Vassen, and D. Stover (2004), Ceramic materials for thermal barrier coatings, Journal of European Ceramic Society, 24, 1-10.

White, B. D., Kesler, O. and Rose, L. (2008), Air plasma spray processing and electrochemical characterization of SOFC composite cathodes, Journal of Power Sources, vol. 178, no. 1, pp. 334-343.

Sampath, S. (2009), Thermal sprayed ceramic coatings: fundamental issues and application considerations, International Journal of Materials and Product Technology, vol. 35 , no. 3-4, pp. 425-448 